\title{
TAILOR-MADE IT PROJECT MANAGEMENT
}

\author{
Ariel I. La Paz ${ }^{1}$ and Rodrigo I. López ${ }^{2}$ \\ ${ }^{1}$ Faculty of Economics and Business, Universidad de Chile, Chile \\ ${ }^{2}$ Departamento de Ciencias de la Computación, Pontificia Universidad Católica de Chile, Chile
}

\begin{abstract}
IT project management has been studied and documented over recent decades. Topics studied tend to cover the tools, methods and cases of technological developments and systems implementations. In spite of the advances in the knowledge base of project management, still, high rates of failure can be found along with the unmet goals of the IT investments and wasted resources mainly by poor management of technological innovations. The article explores what are the methods, tools and techniques for project management that better fit the diverse and varied initiatives known as IT projects implemented in diverse organizational contexts. In order to manage and systematically analyze the complexity of projects and organizations, ontological frameworks are introduced, and a set of tools and techniques for project management are associated with the different contexts. With a sample of 183 capstone projects developed in an undergraduate senior course for IS design, the authors identified customized sets of tools and methods for project management that adapt to the characteristics of each project.
\end{abstract}

\section{KEYWORDS}

Project Management, Ontological Frameworks, Toolset for IST Project, IT Project

\section{INTRODUCTION}

IT project management methods and tools formally sprung over the last three decades, since the publication of standards and methods for IT project management such as the Project Management Book of Knowledge (PMBOK), Projects in Controlled Environment (PRINCE) (Matos and Lopes, 2013), KANBAN, more recently SCRUM (Takeuchi and Nonaka, 1986, Cockburn and Highsmith, 2001), and many variations of these and other methods for project management. The methods and standards for IT project management appeared as a response to the development and implementation of Information Systems and Technologies (IST) and software development in organizations all over the world, and are based on project management methods aiming to standardize tools, practices and roles since the late 1950s (Garel, 2013). The emergence, sophistication and effectiveness of the IT project management methods and models have not proven to follow the same pace of the technological evolution or the increasing demands of companies adopting IST (Hoffman, Ahlemann and Reining, 2020; Mir and Pinnington, 2014). The former translates into poor statistics of IT project success, high rates of delay and cost overruns, not to mention the user's frustration and corporate value losses (Papke-Shields et al., 2010). Several publications reveal success rates in the implementation of projects below $30 \%$, associating such rates to several reasons, with most causes rooted in the mismanagement of project planning and execution, rather than failures explained by technological issues (Nelson, 2007).

Project management methods vary from structured to agile, descriptive to prescriptive, rigid to flexible (Špundak, 2014) and include management dimensions or areas such as budget, people, risk, communications, documentation, or scope (Radujković and Sjekavica, 2017). The management dimensions suggest the use of tools and techniques to plan and monitor the use of resources, as well as to verify the accomplishment of the project objectives for the client, assisting the project manager in achieving more predictable results (Joslin and Müller, 2015). In spite of a sound theorization of IT Project management, failure rates do not seem to decrease (Nelson, 2007, Mir and Pinnington, 2014). Improving the methods, techniques and use of tools for IT Project management is critical in an increasingly demanding scenario of technological transformations in all types of organizations, and the imminent advent of even more expectedly pervasive technologies such as 5G, quantum computing, artificial intelligence, and sensors that pave the road for Industry 4.0 (Rao and Prasad, 2018, Lasi et al., 2014). 
Scholars in the field argued that there is a strong relationship between the use of good practices and success in project management. Joslin and Müller (2015) found that the application and use of comprehensive methodologies lead to higher levels of success. Academic publications in IT project management present case studies, methods comparisons, or history and trajectory of methods, revealing the need for adapting project management methods and tools to improve the management process itself, as well as the final product success (Garel, 2013). In spite of some general directions to choose methods (for example, according to size and complexity), there is neither a unified theory of project management (Garel, 2013, Špundak, 2014), nor concrete ideas of how to customize and apply methods and tools to the different project characteristics, so that the probability of success increases. Even though the current success rates are rather low compared with the amounts of investments and technological potential, it is good and positive to have a variety of methods and approaches to manage IT projects where project managers can choose from. Then, choosing the right method or approach to manage a given project is as critical as it is to choose the right technology. Nelson (2007) synthesizes the postmortem learning from ten failed IT projects and concludes that most failure causes relate first to the IT project management process, second to issues with stakeholders and people involved in the project, and just a minority of causes relate to technology. Hence, our motivation is to better understand how the selection of methods, approaches and tools for IT project management can be adapted for the effective and efficient management of IST adoption. The research question we aim to answer is: How can the selection of methods and tools for IT project management be systematically formulated to improve the probability of success? The premise behind the pursued answer is that the mere existence of methods and certifications for IT project management does not suffice for success, but that the strategic selection and application of tools could be an alternative approach to customize the toolkit for project managers.

To answer our research question, two ontological frameworks are presented in section 2 , in order to seize the complexity of IST project management and organizational context, and to explore the feasibility to use them to systemically and systematically characterize a given project, and then choose the right tools for its management. Section 3 explains how the ontological frameworks are used to analyze a set of IST projects. The main findings of this research, presented in section 4 , are not yet conclusive, but open alternative avenues to study the mechanisms for failure and success in IST projects, as well as to customize the set of tools used in the management of IST projects, as explained in section 5.

\section{ONTOLOGICAL MODELING}

Complex phenomena are usually modeled by simplification and reduction of the variables that represent the causes, correlations and effects. IST project management methods have been modeled by stages and dimensions, or according to the structured or agile approaches towards the project. Such analyses provide general rules for the association of methods and projects, indicating what methodologies better suit the project type according to the size of a project, available time to completion, the experience of a company conducting technological projects, or the organizational understanding of the purpose. This research applies ontological modelling to the key areas of project management, in a similar fashion as it has been developed in other areas of IST (Vasquez and La Paz, 2019; La Paz et al 2019)

However, the complexity of a project to be managed under a particular organizational context is for much larger than generic dimensions, stages and traditional tools, being the dimensions a subject of study for project success (Papke-Shields et al., 2010). On one hand, there are many different things called IST projects, from the very technical integration of software architectures, or back-office migration of data, to the strategic implementation of business analytics tools to support decision-making processes. On the other hand, the organizations where these IST projects are implemented also present multiple characteristics and differences as well, for example, industry, size, maturity or organizational structure. Both entities (project and organization) present complexities and particularities that affect the selection and the effectiveness and efficacy of methods and tools for the management of the resources and the achievement of objectives (Serrador and Turner, 2015). The following sub-sections introduce ontological frameworks to describe systematically the complexities of projects and organizations. 


\subsection{IST Project Ontology}

Essentially, FTP is a client-server protocol that facilitates the transfer of files between two IST projects are hardly standardized. The implementation of the same software in two companies in the same industry, and with similar conditions may find diverse difficulties and produce very different results. A project may start from scratch, while others start from an installed infrastructure with processes, data and applications already in use, implying pros and cons to be differently managed in each case. With an ontological framework, we organize the dimensions lifecycle stage, acquisition strategy, operation objective, and the IT structure to systematically characterize an IST project. Each dimension is represented by a column containing a taxonomy and arranged to be read from left to right to form phrases describing a given IST project. The taxonomies are taken from generic available descriptions in the Management Information Systems (MIS) field.

Table 1. IST project ontological framework

\begin{tabular}{|c|c|c|c|c|c|}
\hline Lifecycle stage & & Acquisition strategy & & $\begin{array}{l}\text { Operation } \\
\text { objective }\end{array}$ & IT structure \\
\hline $\begin{array}{l}\text { Planning } \\
\text { Analysis } \\
\text { Design } \\
\text { Implementation }\end{array}$ & $\frac{\tilde{\Xi}}{\delta}$ & $\begin{array}{l}\text { In-house development } \\
\text { Packaged software purchase } \\
\text { Outsourcing } \\
\text { Cloud service }\end{array}$ & 2 & $\begin{array}{l}\text { Create } \\
\text { Read } \\
\text { Update } \\
\text { Delete }\end{array}$ & $\begin{array}{l}\text { Software } \\
\text { Hardware } \\
\text { Networks } \\
\text { Data } \\
\text { Persona } \\
\text { Process } \\
\text { Policy }\end{array}$ \\
\hline
\end{tabular}

The IST project ontological framework presented in Table 1 contains 448 possible combinations to describe any particular project. One example of the combinations for a project is "Planning of an in-house development to create software", while a second different combination is "Implementation of a cloud service to delete policy". The first example takes the first element from each taxonomy, and the second example takes the last element from the taxonomies. Other 446 different elements can be built by concatenating the elements from the columns and connectors. One project could use more than one element from each dimension to characterize itself, and with its particular definition, choose and apply methods and tools for effective and efficient management.

\subsection{Organizational Context Ontology}

A second ontological framework is presented in this subsection to represent the complexity of organizational context, which significantly impacts the implementation of IST. Different studies have portrayed the organizational complexity by the analysis of constructs such as size, culture, country, and industry (See a summary of measures used in project management in Papke-Shields et. al (2010). Our study captures the organizational complexity and variability by defining taxonomies for Company size, Maturity, Structure type, and Industry. Other constructs such as culture type, focus on efficiency, sustainability, customer satisfaction, or operations scope could be included, but in order to preserve the parsimony of the ontological framework, and to use of well-known taxonomies, we decided to use only four main concepts. The reader could modify the framework to make it more comprehensive by adding new columns or terms to the taxonomies if s/he needs to make an even more precise characterization of the organizational context, but the logic of the representation is presented here in Table 2.

The ontological framework introduced to represent the organizational context contains 1,500 different combinations, calculated as the multiplication of the elements of each dimension that form the instances of the ontology as one selects one element from each column and combines with the connecting phrases and the elements of subsequent columns. A few examples of different organizational contexts are:

- Small emergent company, with hierarchical structure in finance \& insurance

- $\quad$ Large structured company, with matrix structure in manufacturing

- $\quad$ Medium initial company, with linear structure in educational services

- $\quad$ Large optimized company, with divisional structure in retail trade

- $\quad$ Small integrated company, with inverse structure in professional, scientific \& technical services 
Implementing the same IST project in each illustration -for example, a payroll system-, would need different tools, techniques and methods for project management, given the specific labor norms that may apply to each industry and country, the contract types that each organization offers to their employees, the number of employees or the organizational culture, to name a few differentiating aspects that affect the implementation of a payroll system.

Table 2. Organizational context ontological framework

\begin{tabular}{|c|c|c|c|c|c|}
\hline $\begin{array}{l}\text { Company } \\
\text { size }\end{array}$ & Maturity & & $\begin{array}{l}\text { Structure } \\
\text { Type }\end{array}$ & & Industry \\
\hline $\begin{array}{l}\text { Small } \\
\text { Medium } \\
\text { Large }\end{array}$ & $\begin{array}{l}\text { Initial } \\
\text { Emergent } \\
\text { Structured } \\
\text { Integrated } \\
\text { Optimized }\end{array}$ & 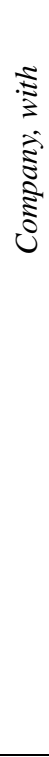 & $\begin{array}{l}\text { Linear } \\
\text { Matrix } \\
\text { Hierarchical } \\
\text { Divisional } \\
\text { Inverse }\end{array}$ & 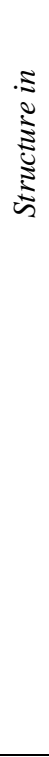 & $\begin{array}{l}\text { Agriculture, forestry, fishing and hunting } \\
\text { Mining, quarrying, oil \& gas extraction } \\
\text { Utilities } \\
\text { Construction } \\
\text { Manufacturing } \\
\text { Wholesale trade } \\
\text { Retail trade } \\
\text { Transportation and warehousing } \\
\text { Information } \\
\text { Finance \& insurance } \\
\text { Real estate and rental \& leasing } \\
\text { Professional, scientific and technical services } \\
\text { Management of companies and enterprises } \\
\text { Administrative and support and waste management al } \\
\text { remediation services } \\
\text { Educational services } \\
\text { Health care and social assistance } \\
\text { Arts, entertainment and recreation } \\
\text { Accommodation and food services } \\
\text { Public administration } \\
\text { Other services }\end{array}$ \\
\hline
\end{tabular}

\subsection{Relation of Tools with Projects and Organizational Contexts}

The two ontological frameworks present fairly large numbers for IST project types and organizational contexts, even with relatively small ontological frameworks. Combining the numbers of both frameworks, we could calculate the even larger product $(448 \times 1,500=672,000)$ that reveal an exponential complexity of the IST project management, given that each of the 448 types of projects could be executed in any of the 1,500 different organizational contexts. These numbers could be increased or reduced by adding, refining or removing components in the taxonomies, but the message and point the authors make is that complexity and variety of projects is by far larger than the number of methods, tools and techniques for IST project management.

The revealed variety, indirectly indicates that any particular method for project management containing subsets of tools and techniques, most likely not fit all the possible combinations of projects and contexts. Likely, some methods and approaches support better certain projects and contexts, and some other projects and contexts require different sets of tools, techniques, approaches or methods for their better execution. It is to say that given the particularities of a project and the organization executing it, it may be more effective to use lean and agile methods, taking advantage of reduced costs and time, while in some other context it is more convenient to use more traditional and comprehensive methods with multiple tools and at a higher monitoring cost. In between the extremes of the different methods for IT project management, intermediate projects may need particular combinations of the methods, tools and techniques, balancing the effectiveness and efficiency of particular sets of tools. With such logic, we surveyed the most used methods, in their original versions, to identify their classic tools and techniques, finding a list of 122 tools contained in the widely used methods for project management, and commonly applied during the execution of IT projects.

It should be noted that the tools present different levels of application, and some tools contain or use other tools as components (Figure 1 presents an example of main tools and subcomponents). The identification of the tool's subcomponents facilitates its use, by making sense to the users and stakeholders of the project, and allows projects with a smaller budget to focus the resources on those tools that maximize the effectiveness of management on the project. 


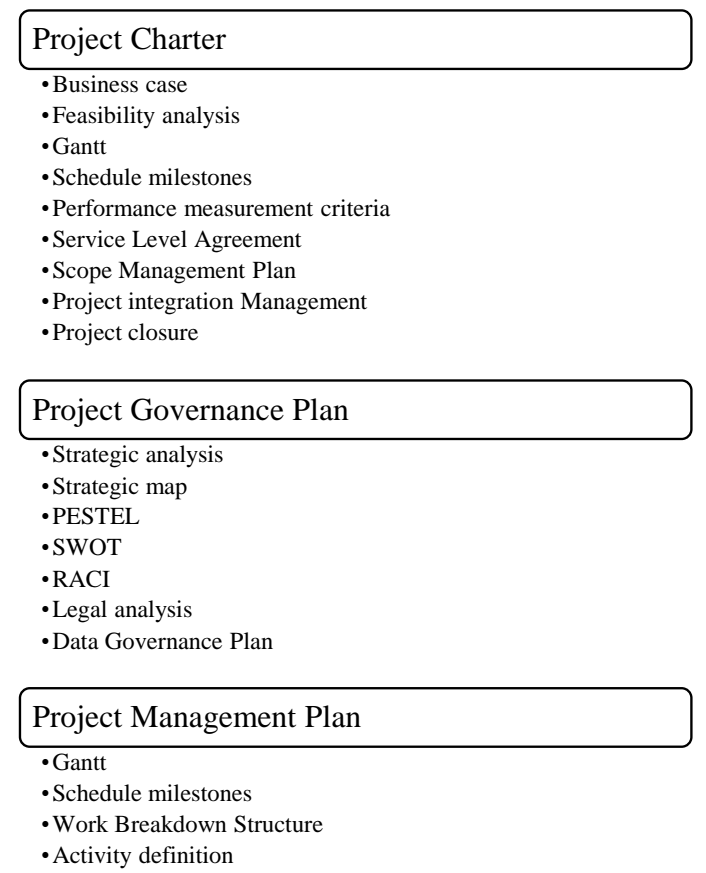

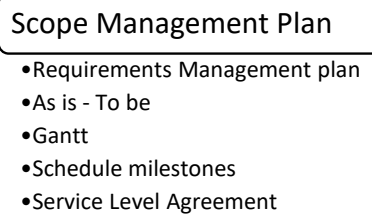

Requirements Management plan

-Functional requirements

- Technical requirements

- Cause and effect diagram

- Requirements prioritization

-Requirement Traceability Matrix

Risk Management Plan

-Risk map

- Risk coverage definition

-Regulatory Compliance Assessment

- Business continuity planning

-Recovery Plan

Figure 1. Main composite tools for IT project management

The task was then to associate tools and techniques to particular combinations of IST project types and organizational contexts to systematically analyze and identify trends or patterns to customize sets of tools according to the project and context types.

\section{METHOD FOR THE ONTOLOGICAL ANALYSIS}

A main expected result, is to deliver contextualized - tailor-made - information to the IST project management teams, according to the stage/size/complexity of the project, by selecting a set of relevant tools that significantly, effectively and efficiently assist the project manager in monitoring, tracking, and executing the project with his/her team and the stakeholders. By using the ontological frameworks as lenses to analyze the particularities of projects and organizations, it is possible to systematically characterize the different instances for the implementation of IST projects and specifically recommend and choose tools, techniques and methods for project management. Given the number of combinations from the ontologies, the authors prepared partial combinations of ontological dimensions to represent by extension the projects and contexts in which tools for management are required. Then assigned, by using expert judgment, the most appropriate tools from the list of 122 items to each instance identified.

Several iterations of tools' assignment to the partial dimensions of the ontologies were made, and subsequently integrated as the combinations of the ontologies were reconstructed. First the union of all combinations, and then the intersection of combinations and tools allowed us to assign particular sets of tools and techniques for project management in specific organizational contexts, and for each type of IST project.

In order to test the validity of the tools assignment to such a large number of combinations, a sample of 183 capstone projects developed by senior students in an undergraduate course of Information Systems Design were analyzed and mapped onto the ontological frameworks by the authors of this article. In these projects, students design information systems prototypes for companies with real-life problems and document the analysis process. Each project was characterized and mapped onto the ontologies with the information available from project reports and presentation records. Finally, the sets of tools and techniques associated with each project were retrieved from the initial assignment of tools and techniques for IST project management to the ontological frameworks. 


\section{RESULTS}

In the projects mapped, the ontological analysis suggested an average of 75 tools, a maximum of 104, and a minimum of 44 tools subsets. Although some tools are recommended in a large proportion of the capstone projects, the composition of the sets of tools differs according to the characteristics of each project and the context of each organization. Table 3 illustrates toolsets recommended for 2 projects, which have similar characteristics in terms of producing prototypes at initial stages of IST projects, but that have different stages in the systems development cycle, organizational contexts, and project characteristics. The illustrations have been selected to present the project wit minimum and maximum number of tools recommended from the ontological analysis.

Table 3. Examples of sets of tools recommended for IT project management

\begin{tabular}{|c|c|c|c|}
\hline \multicolumn{4}{|c|}{ Project Id 87: Design of a Balanced Scorecards for a private nursery } \\
\hline Planning & Analysis & Design & Implementation \\
\hline \multicolumn{4}{|c|}{ Integration } \\
\hline
\end{tabular}

In the sample of capstone projects analyzed, some projects require large numbers of tools, numbers that may exceed the budget assigned for the administration of such technological initiatives in these types of organizations. A more detailed review of these projects confirmed that they tend to correspond to organizations with weak organizational definitions, minimum experience or maturity to manage or develop IST projects that translate into insufficient strategic definitions, absence of documentation and process mapping procedures, insufficient staffing, among other characteristics. Organizations with those features may need to use larger sets with multiple tools as a way to face their weaknesses. Given the need to use more tools to manage a project, and considering the usual budget constraints it is foreseeable that these projects would present more difficulties for their completion, beyond the project definition, that reduces its chances to succeed. On the other hand, projects with reduced complexity and with proper strategic definitions may need a smaller but agile and economic set of tools than a traditional method may indicate. 
Table 3. Examples of sets of tools recommended for IT project management (continued)

\begin{tabular}{|c|c|c|c|}
\hline \multicolumn{4}{|c|}{ Project Id 60: Financial and operational control system in a Spa } \\
\hline \multicolumn{4}{|c|}{$\begin{array}{l}\text { The project presents an aesthetic center dedicated to non-invasive treatments in the body and facial area, the company faces high } \\
\text { competition in the sector, which drives it to seek new forms of differentiation, unfortunately, it lacks automated systems that support } \\
\text { the management of the business operation, so it is proposed as a solution the design of an operational and financial control system. }\end{array}$} \\
\hline Planning & Analysis & Design & Implementation \\
\hline $\begin{array}{l}\text { Budget execution } \\
\text { Business case } \\
\text { Business continuity planning } \\
\text { Business Expert judgment } \\
\text { Business Recovery Plan } \\
\text { Canvas } \\
\text { Communication protocols } \\
\text { Decision maker Feedback } \\
\text { Detractors identification } \\
\text { Economic Value Added } \\
\text { Incentive program } \\
\text { Job definition } \\
\text { Legal analysis } \\
\text { Monte Carlo simulation } \\
\text { Net Present Value } \\
\text { Payback } \\
\text { Policies for distribution and } \\
\text { access to information } \\
\text { Procurement Management } \\
\text { Plan } \\
\text { Project closure } \\
\text { Regulatory Compliance } \\
\text { Assessment } \\
\text { Requirements Management } \\
\text { plan } \\
\text { Risk coverage definition } \\
\text { Service Level Agreement } \\
\text { Strategic analysis } \\
\text { Strategic map } \\
\text { Test Plan } \\
\text { Total Cost Ownership } \\
\text { Zone of possible agreement } \\
\text { (ZOPA) }\end{array}$ & $\begin{array}{l}\text { Activity definition } \\
\text { Brainstorming } \\
\text { Business case } \\
\text { Business continuity planning } \\
\text { Business Expert judgment } \\
\text { Business Recovery Plan } \\
\text { Canvas } \\
\text { Cases of use } \\
\text { Communication protocols } \\
\text { Cost Management Plan } \\
\text { Data flow diagram } \\
\text { Decision maker Feedback } \\
\text { Detractors identification } \\
\text { Flowchart } \\
\text { Functional requirements } \\
\text { Identification of Users } \\
\text { Job definition } \\
\text { Legal analysis } \\
\text { Performance analysis } \\
\text { Policies for distribution and access to } \\
\text { information } \\
\text { Process engineering } \\
\text { Process indicators } \\
\text { Procurement Management Plan } \\
\text { Requirement Traceability Matrix } \\
\text { Requirements Management plan } \\
\text { Requirements prioritization } \\
\text { Resource Management Plan } \\
\text { Risk coverage definition } \\
\text { Standards Check } \\
\text { Strategic analysis } \\
\text { Strategic map } \\
\text { Systems architecture } \\
\text { Test Plan } \\
\text { Total Cost Ownership } \\
\text { Training program identification } \\
\text { User roles } \\
\text { User segmentation } \\
\text { User stories } \\
\text { Zone of possible agreement (ZOPA) }\end{array}$ & $\begin{array}{l}\text { Activity definition } \\
\text { Brainstorming } \\
\text { Business Expert judgment } \\
\text { Canvas } \\
\text { Cases of use } \\
\text { Data flow diagram } \\
\text { Employee role definition } \\
\text { End user Feedback } \\
\text { Flowchart } \\
\text { Functional requirements } \\
\text { Identification of Users } \\
\text { Incentive program } \\
\text { Interaction Guide } \\
\text { Job definition } \\
\text { Job description } \\
\text { Process engineering } \\
\text { Process indicators } \\
\text { Product Recovery Plan } \\
\text { Prototypes } \\
\text { Requirement Traceability } \\
\text { Matrix } \\
\text { Requirements prioritization } \\
\text { Standards Check } \\
\text { Systems architecture } \\
\text { Technical requirements } \\
\text { Technological Expert } \\
\text { judgment } \\
\text { Total Cost Ownership } \\
\text { Training program } \\
\text { identification } \\
\text { User modeling } \\
\text { User role definition } \\
\text { User roles } \\
\text { User segmentation } \\
\text { User stories } \\
\text { Wireframe } \\
\text { Zone of possible agreement } \\
\text { (ZOPA) }\end{array}$ & $\begin{array}{l}\text { Budget execution } \\
\text { Cost Management Plan } \\
\text { End user Feedback } \\
\text { Functional requirements } \\
\text { Interaction Guide } \\
\text { Performance analysis } \\
\text { Product Recovery Plan } \\
\text { Project closure } \\
\text { Prototypes } \\
\text { Regulatory Compliance } \\
\text { Assessment } \\
\text { Requirement Traceability } \\
\text { Matrix } \\
\text { Resource Management } \\
\text { Plan } \\
\text { Service Level Agreement } \\
\text { Standards Check } \\
\text { Systems architecture } \\
\text { Technical requirements } \\
\text { Technological Expert } \\
\text { judgment } \\
\text { Test Plan } \\
\text { User modeling } \\
\text { User segmentation } \\
\text { User stories } \\
\text { Wireframe }\end{array}$ \\
\hline \multicolumn{4}{|c|}{$\begin{array}{ll}\text { Integration } \\
\end{array}$} \\
\hline $\begin{array}{l}\text { Appendix } \\
\text { As is - To be } \\
\text { Benchmark } \\
\text { Brand design } \\
\text { Budget } \\
\text { Change Control System } \\
\text { Change management } \\
\text { Communication Management } \\
\text { Plan } \\
\text { Data dictionary } \\
\text { Data Governance Plan } \\
\text { Expert judgment } \\
\text { Feedback }\end{array}$ & $\begin{array}{l}\text { Financial indicators } \\
\text { Focus group } \\
\text { Gantt } \\
\text { Implementation Plan } \\
\text { Interaction Plan } \\
\text { Interview key people } \\
\text { IT Infrastructure Metadata } \\
\text { Knowledge Management Plan } \\
\text { Meeting Agenda } \\
\text { Meeting minutes } \\
\text { Meetings } \\
\text { Mentoring }\end{array}$ & $\begin{array}{l}\text { Minute of Agreement } \\
\text { Negotiation } \\
\text { Performance Incentive Plan } \\
\text { Process Mapping } \\
\text { Project Charter } \\
\text { Project Governance Plan } \\
\text { Project Management Plan } \\
\text { Quality Management Plan } \\
\text { RACI } \\
\text { Recovery Plan } \\
\text { Recruitment and selection } \\
\text { Risk Management Plan }\end{array}$ & $\begin{array}{l}\text { Risk map } \\
\text { Schedule milestones } \\
\text { Scope Management Plan } \\
\text { Staffing } \\
\text { Stakeholder Engagement } \\
\text { Plan } \\
\text { Stakeholder matrix } \\
\text { Talent development } \\
\text { program } \\
\text { Training Management } \\
\text { Plan } \\
\text { Work Breakdown } \\
\text { Structure }\end{array}$ \\
\hline
\end{tabular}

Problems in the management of IST projects are subsequently attributed to the technology, its management, or the chosen management methodology when some of these issues can be solved or minimized with a better selection of tools and techniques for project management. 
Figure 2 shows the grouping of the tools recommended to the 183 capstone projects into word clouds. In this figure, the word clouds have been grouped around the IS lifecycle stages, planning, analysis, design and implementation, and added an integration category. The size of the tool's names illustrate the frequency of assignments by expert judgment applied into the ontological design. Considering tools with a higher frequency, and cases where the purposes and objectives of the projects are clear and shared by the company, the Regulatory Compliance Assessment, the Risk Coverage definition and a Legal analysis help diagnose and assess project risks. The Zone of possible agreements for negotiation and the Functional and Technical requirements for the IST project help to define the scope of the project and manage the expectations of stakeholders. Finally, the prevalence of the Change Control System and Stakeholder Engagement Plan as tools for integration provide the management team a way to control the adjustments to the project during its life cycle, taking into account the stakeholders and the way in which they get involved. These tools and methods identified from the ontological design, are not usually recommended from the traditional methodologies (Papke-Shields et al., 2010).

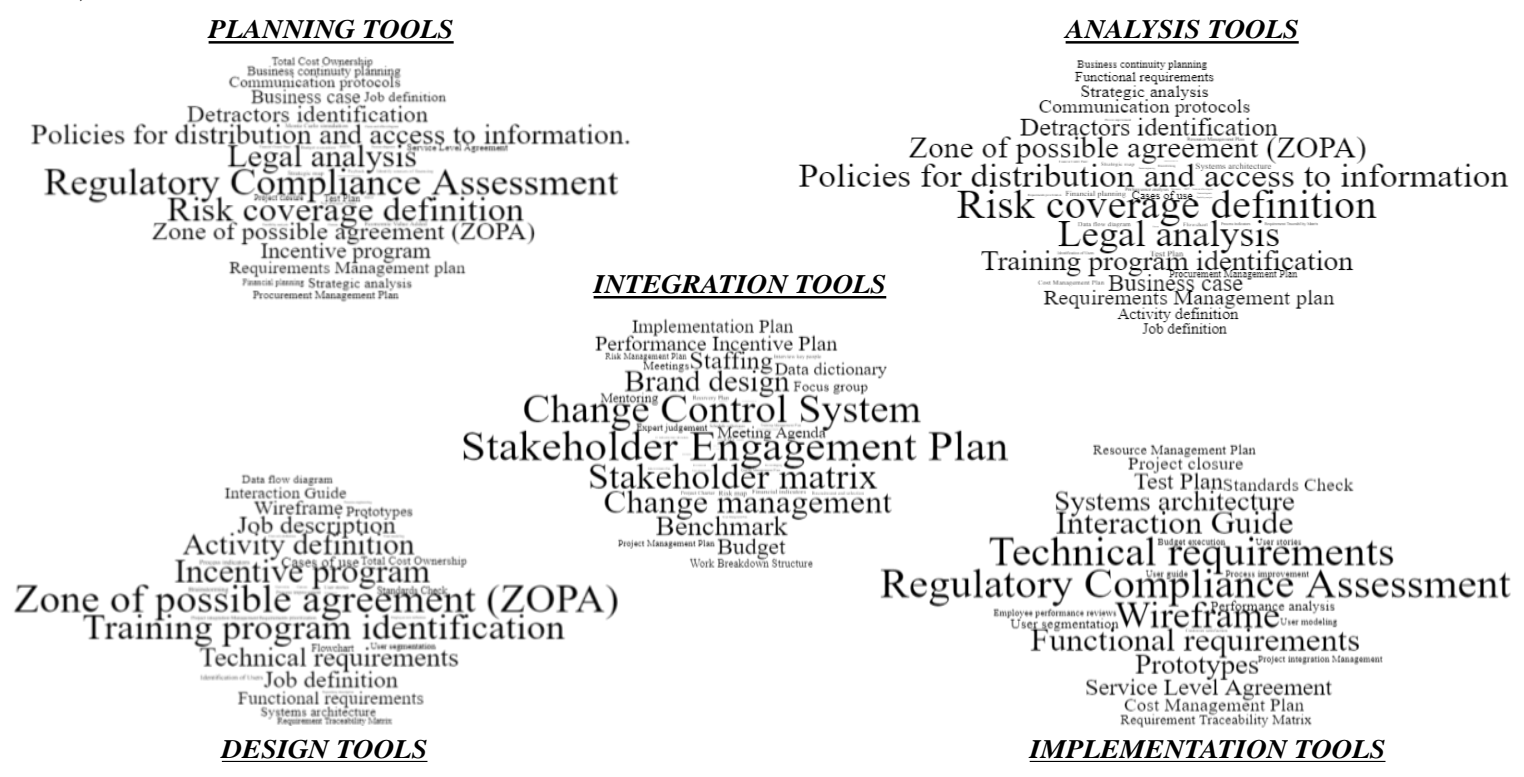

Figure 2. Recommended tools word clouds

\section{CONCLUSIONS}

The complexity of project management is usually approached with the development of specific methods, thought as standardized products out of the best practices. The complexity of the IST projects analyzed and revealed in this study, by means of representing the variety of projects and organizational contexts, reinforces the view of the authors about the difficulties to standardize with a few methods, the management of an increasing number and types of information systems and technology projects. Then, the association of the appropriate sets of tools, techniques or methods to each particular project needs a more precise definition of the project and context to be recommended to a large variety of projects.

The ontological frameworks represent practical tools to describe projects and contexts, and the association of tools and techniques for project management to a large number of combinations contained in the frameworks facilitates the customized selection of the corresponding sets that assist the strategic effective, efficient and economic use of tools and methods. In our study, the association of tools and projects and contexts is based on the expert judgment of the authors, which has been pre-designed and incorporated into the ontological modeling and analysis. Simultaneously, the tailor-made association of these tools, permits to discard the use of methods that are expensive and ineffective under the wrong context of a project. No tool or method will be complete or sufficient for all projects, and hence the need to customize their selection and use to improve the current rates of success and to optimize the costs of their management. Our analyses present such differences in the number and type of tools required for effective and efficient IT project management contrasting the elements in table 
3 for two projects, and later in Figure 2, it is represented how some tools are recommended in more projects. The emphases in recommendations of tools and techniques should be directed by the nature of the project and organizational context, hence, customizing in each case the toolkit for the manager and his team. In some cases, it is expected that the set of tools and techniques could be assimilated with some method (i.e., agile, lean, or structured), while in some other cases, the recommended toolkit may be a composite method mixing tools, techniques and good practices from different approaches towards IT Project management.

The present study can be improved by increasing the number of projects analyzed and including in the sample other projects that can be evaluated ex post, after the successful or failed use of traditional methods. With a larger and more diverse sample of IST projects covering the whole IS lifecycle and IT project Lifecycle, more tools could be analyzed and prioritized. As future research, the tools could be systematically analyzed and prioritized according to some degree of contribution for the improvement of the success rates on each IST project.

\section{REFERENCES}

Cockburn, A. \& Highsmith, J. (2001). Agile software development: The people factor. Computer, 131-133.

Garel, G. (2013.) "A history of project management models: From pre-models to the standard models. International Journal of Project Management (31), 663-669.

Hoffmann, D., Ahlemann, F., \& Reining, S. (2020). Reconciling alignment, efficiency, and agility in IT project portfolio management: Recommendations based on a revelatory case study. International Journal of Project Management, 38(2), 124-136, doi:https://doi.org/10.1016/j.ijproman.2020.01.004.

Joslin, R. \& Müller, R. (2015.) Relationships between a project management methodology and project success in different project governance contexts. International Journal of Project Management (33), 1377-1392.

La Paz, A., Merigó, J., Powell, P., Ramaprasad, A., \& Syn, T. (2019). Twenty-five years of the Information Systems Journal: a bibliometric and ontological overview. Information Systems Journal. https://doi.org/10.1111/isj.12260

Lasi, H., Fettke, P., Kemper, H.-G., Feld, T. \& Hoffmann, M. (2014.) Industry 4.0. Business information systems engineering (6), 239-242.

Matos, S. \& Lopes, E. (2013.) Prince2 or PMBOK-a question of choice. Procedia Technology. (9), 787-794.

Mir, F. A. \& Pinnington, A. H. (2014.) Exploring the value of project management: linking project management performance and project success. International journal of project management (32), 202-217.

Nelson, R. (2007) IT project management: Infamous failures, classic mistakes, and best practices. MIS Quarterly executive (6)

Papke-Shields, K. E., Beise, C. \& Quan, J. (2010.) Do project managers practice what they preach, and does it matter to project success? International journal of project management (28), 650-662.

Radujković, M. \& Sjekavica, M. (2017.) Project management success factors. Procedia engineering (196), 607-615.

Rao, S. K. \& Prasad, R. (2018.) Impact of 5G technologies on industry 4.0 Wireless personal communications (100), 145-159.

Serrador, P. \& Turner, R. (2015.) The relationship between project success and project efficiency. Project management journal (46), 30-39.

Špundak, M. (2014.) Mixed agile/traditional project management methodology-reality or illusion? Procedia Social Behavioral Sciences (119), 939-948.

Takeuchi, H. \& Nonaka, I. (1986.) The new product development game. Harvard business review (64), 137-146.

Vásquez, J., \& La Paz, A. (2019). The Knowledge Body of Requirement Engineering in IST Innovations: An Ontological Analysis. Journal of technology management \& innovation, 14(4), 78-84. 